\title{
Quaternary research: introductory words
}

\author{
Paul Woldstedt \\ Amt für Bodenforschung, Am kleine Felde 12, 3000 Hannover, Germany \\ Correspondence: $\quad$ Frank Preusser (frank.preusser@geologie.uni-freiburg.de) \\ Relevant dates: $\quad$ Published: 17 December 2021
}

How to cite: $\quad$ Woldstedt, P.: Quaternary research: introductory words, DEUQUA Spec. Pub., 3, 5-9, https://doi.org/10.5194/deuquasp-3-5-2021, 2021.

Special issue statement. This article is part of a special issue published on the occasion of the 70th anniversary of $E \& G$ Quaternary Science Journal (EGQSJ). The special issue celebrates the journal's notable contribution to Quaternary research by revisiting selected milestone articles published in the long history of EGQSJ. The German Quaternary Association (DEUQUA) presents translations of the originals and critical appraisals of their impact in tandem anniversary issues of DEUQUASP and EGQSJ, respectively.

Original article: https://doi.org/10.3285/eg.01.1.01

Translators: Clare Bamford, Frank Preusser and Henrik Rother

At the dawn of the geological presence stands a very peculiar global climate change. While during the Tertiary period thermophilic trees still grew at the Arctic Circle, temperatures from then on and all over the world gradually began to fall, and large glaciations started to form at the poles and in the high mountains. Glaciers descended ever deeper into the valleys, and inland ice penetrated ever further into the temperate zone. The climate belts of the Earth shifted. At the same time, sea levels fell all over the Earth, returning large areas of the previously flooded shelf to the mainland.

However, this drop in temperature and growth of glaciations from the poles towards the equator and from the high mountains into the valleys was not a singular event. Instead, the process was repeated three or four times with glaciers expanding and sea levels falling. In between were long periods - thousands of years - in which the climate was as it is today and in which the sea and land were of a similar size to what they are now. Or was it, as some researchers assume, only one hemisphere at a time where these processes took place, or from which they at least started? This is the first important problem. It seems to be more likely that both hemispheres were affected at the same time. What was the cause of this strange, worldwide shift with all its accompanying symptoms? Diverse hypotheses and mathematically elaborated theories have been proposed - but in essence, we still do not have a satisfactory explanation for the cause and the manifold phenomena of the Ice Age.

The geological formation characterised by the great glaciations is called the "Quaternary"; we will come back to this later. The field of science dealing with the Quaternary is called Quaternary research or - if we only consider the main subject - Ice Age research. Not only the phase of Earth history known as the Quaternary stands in front of us as a major unresolved problem; another enormously important fact puzzles us: during the Ice Age, which fills the last half or full million years of the estimated age of the Earth, at least 1500 million years in total, mankind emerged from the darkness of his animal existence and ascended to higher culture. Are both events, the strange climate change on Earth and the awakening of mankind, connected? Did the climatic upheaval provide a stimulus, so to speak, that fostered our own human development? Or is it only by chance that both events occurred at about the same time? This is another mystery that still needs to be resolved.

This is not the place to give a full overview of the development of our knowledge of the Ice Age and the changing view of the various problems. Rather, it can only be about this: which problems have arisen and what methods have so 
far been developed to resolve them? The basic problem, the clarification of the cause of the drastic climate change, we have already mentioned above, as well as the other important question of the origin and development of mankind.

If we go into the details, we find a wealth of questions and an equal number of attempts to address the whole problem by solving one or the other individual question. Of foremost importance is the detailed clarification of the order in which the Ice Age unfolded. A sequence of these events across vast areas must be determined, i.e., we aim at reconstructing the full stratigraphy of the Ice Age and its regular succession of superimposed deposits from countless profiles.

Only an exact stratigraphy allows, for example, a proper placement of finds of prehistoric humans and their tools into the such a sequence of events. The basic classification of the human cultures during the Ice Age was developed in France (Gabriel de Mortillet and others). There, an infinitely richer collection of material left behind by Ice Age humans is available than in Germany. Nevertheless, a correct chronological classification of humans within the sequence of the glacial and interglacial periods in France did not succeed at first. Initially, a view took hold that the cultural development of mankind had only begun during the last interglacial period and thus survived only one glaciation, the last glacial period. It thus marked a leap in our understanding when the stratigraphic classification of the prehistoric finds of Markkleeberg and Hundisburg proved beyond doubt that cultured humans had experienced at least one earlier glacial cycle. Hence, the cultural development of mankind must have begun tens of thousands of years earlier than hitherto thought.

But is the cultural development of mankind even tenths of thousand years older, perhaps 100000 years or even much more? How can we know that? Are these not vague and unjustified figures? Can we not equally give estimates of 10000 or 1000000 years? This brings us to a new problem: the attempts to establish a more precise determination of age, i.e., to establish an absolute chronology of the Ice Age. Methodologically, attempts to solve this problem have originated from different sides. By counting the layers of sand and clay deposited in water through annual cycles - annual strata so to speak - de Geer and his students have attempted to determine the duration of the late and post-glacial periods by years. It is not a question of whether mistakes were made in individual cases - the age reconstructed dimensions are correct, and this represents a tremendous advance in our knowledge.

New methods for exact chronology have recently been added: besides the "annual ring research", which is based on counting the annual rings of trees, notably the "radiocarbon method", has been developed in North America. The content of radioactive carbon in wood and other organic substances seems to allow an extraordinary precise age determination of such finds. Finally, there is the fluorine method, which is based on the increase in the fluorine content in bone, which at the very least allows a relative classification of the finds.
Further attempts to establish an absolute chronology of the Ice Age relies on astronomical considerations. Here, the sun radiation curves of Milankovitch and Spitaler, which have been much discussed in recent years, have to be mentioned. They attempt to give a structure of time by millennia for the entire Ice Age. The correctness of these theories has been strongly doubted. But they must be mentioned as attempts to arrive at fixed, numerical ideas about the length of time periods during the Ice Age. In any case, it is interesting to note that the orders of magnitude that emerge are similar to those that have been proposed by Albrecht Penck, estimated decades earlier on the basis of weathering depths.

Completely different problems, however, arise when we consider the animal and plant world of the Ice Age. The extension of great glaciations far into the temperate latitudes, in North America down to and below $40^{\circ}$ south, was of profound influence for both. Belts of plants and animals shifted ahead of the ice masses. The hardest selection began. Today, the distribution of plant and animal life in large areas of the Earth's surface is due to the Ice Age. This is of utmost importance for botanists and zoologists. It is worth remembering the chapter on the so-called "relic fauna". The Quaternary researcher, for his part, not only gains valuable markers in flora and fauna for the respective climatic conditions, but also finds characteristic index plants and animals for the individual sections of the Ice Age. A new, special sub-area to be emphasised here is the pollen analysis, which, with the help of the pollen grains of trees, shrubs and herbs preserved in some deposits, provides a picture of the pollen inventory of the different periods. Worth mentioning is also the research on individual animal species, e.g. species of elephant or horse during the different periods of the Ice Age, snails and bivalves in marine and freshwater formations, etc.

But we only need to move on to another area to face new interconnections and new problems. Today, soil science is considered to be of great importance for agriculture and forestry. Significantly, it shall be noted that much of the cultivated soil, especially on the arable land of the cultivated countries, not only in the Old World but also in the New World, is of glacial origin. In Germany, this applies not only to the large North German lowlands and the Alpine foothills, but also to the areas in between these zones, where loess soils as well as soils on glacial terraces and scree formations play an important role. But also the post-glacial pedological processes, such as those within the river and sea marshes, are of great importance regarding their soil development. To understand their origin and the laws of their development is a further task of the Quaternary researcher, just as he is interested in each individual soil profile as it gives him important clues to reconstruct the history of the soil itself.

Again, different relationships and new problems arise when we look at the influence of the Ice Age on the present distribution of land and water, and on the shape of the present coastal outline. Certainly, with a few exceptions, the distribution of land and sea was largely determined by factors other 
than the glacial periods. But the Ice Age, with its rhythmic definition of enormous masses of water in the form of solid ice, caused a tremendous change in the outline of the coast. This was of decisive importance for the entire living world. The British Isles, for example, were several times connected to the mainland and several times isolated islands during the Ice Age. The land that once connected it to France and north-west Germany was consumed most recently by the great post-glacial (Flemish) transgression only 8 to 9 millennia ago. The same applies to other land bridges. Important features in the distribution of flora and fauna can only be understood by these changes in earlier land connections. This is especially true for many prehistoric cultures, whose relationships to others only become understandable when we know about previous land bridges and their interrupted histories.

The fall and rise of the sea level in connection with the locking-up of water during the ice ages (eustatic movements) is also associated with movements related to the depression of the Earth's crust by massive ice loads (isostatic movements). It needs not to be stressed that the study of these ground movements or the transgressive and regressive movements of the seas is of the utmost importance. We need only to recall the question of coastal subsidence in the North Sea. This gives rise to a wealth of problems in all areas and numerous relevant interconnections to neighbouring land areas.

We will now look at the subject and method of Quaternary research from a different angle. First: What do we understand by Quaternary research?

It is the overall exploration of the Ice Age in a broader sense, including the post-glacial period, with all its phenomena. As already mentioned, the geological period characterized by major glaciations, is generally referred to as the Quaternary. Usually, the Pleistocene or Diluvium and the Holocene or Alluvium are distinguished as special substages. An attempt has been made to establish the "Alluvium" as an independent formation. However, there is no justification for this. There is no sign of any significant break that would mark the end of the Ice Age. The disappearance of the inland ice from northern Germany and Scandinavia, for example, is not such a process; it took place at the end of each glacial period. We would then have to make each interglacial period a formation boundary.

According to all we know, the Ice Age as an epoch has not ended. Rather, we are living in an interglacial period, which will most probably be followed by a new glacial period, a glacial period that will perhaps affect Northern Germany in a similar way as the last or penultimate one. Thus, the "Alluvium", the "post-glacial period", must be denied its character as a special formation, which it could only receive because of the strong perspective shortening of the previous one. The subject of Quaternary research is therefore the entire formation from the beginning of the Ice Age to the present.

The Quaternary in its position as the youngest geological formation, in which we presently live, has a very special character that distinguishes it from the older formations. This distinction is based on the temporal position of the Quaternary, as the last geological formation, and on the fact that the Quaternary is the formation of human evolution.

In the field of geology, the most significant method is the stratigraphic reconstruction. "What is younger, what is older?" this is ultimately the critical question in geology. The stratigraphic method is fundamental to Quaternary research, and in this sense Quaternary research is clearly a geological discipline. But there are many other methods from other disciplines that must be employed. From the related field of geography, for example, a very important research method, the morphological analysis, provides critical insights. "Physical Geography" (as part of "General Geology") yields results by direct morphological observations, taking into account relative elevation, river incisions, terrace formation and landform modifications, etc. Albrecht Penck's magnificent classification of the Alpine ice age formations, which in its essence is still valid, was essentially obtained by morphological means.

Since the Quaternary period extends into the presence, there is still the possibility of comparison with the presence, which is not possible for any of the previous geological formations. This provides Quaternary research with very important insights. The conditions of the Pleistocene inland ice can still be studied today in Antarctica, Greenland, Svalbard, Iceland, etc. Thus, the comparative "actualistic" method is not only possible in the Quaternary, but its use is absolutely necessary. The same applies to climatology as the climatology of the currently glaciated areas gives us a key to the understanding glacial climatic conditions.

However, the picture becomes more complex if we look at various neighbouring scientific fields that come into consideration as auxiliary sciences. There is no need to talk about physics and chemistry as they are basic sciences. Some important relationships between botany and zoology and Quaternary research are mentioned above. Anthropology and prehistory are also of great importance. The developmental stages of humanity, the humans of Mauer and Beijing, the Neanderthals, the Aurignac and Cro-Magnon people are index forms of certain periods of the Quaternary. Their tool industries are found in very specific strata and in very specific stratification. Their study is an essential part of Quaternary research and from this point of view, it illuminates the history of the Ice Age.

Numerous other neighbouring sciences also play a critical role in Quaternary research. They can stimulate new Quaternary research, which in turn stimulates the neighbouring sciences. Quaternary research is therefore, according to the scope of its subject and the spectrum of methods used, a science in its own right and one that is of particular importance for the explanation of the presence. As such it represents a distinct "bridging science".

This characteristic as a "bridging science" defines both the strength, but also the weakness of Quaternary research. The strength, as has already been explained, lies in the fact that a multitude of methods and results from neighbouring sci- 
entific fields are concentrated on one area. The weakness is that Quaternary research may be considered a peripheral area for the other sciences, where the geologist, the meteorologist, the geographer, the zoologist, etc., generally does not or only occasionally works in. But this is, given the scope that each of these scientific fields itself has now gained, not to be expected. Anyone who today has to represent the entire field of geology, for example, in research and teaching at a university, covers such a vast field that it will rarely be possible to be fully at home in a peripheral area such as Quaternary research. For the geographer, on the other hand, Ice Age morphology is only a small sub-area in which individual geographers have achieved admirable results, but again it is a marginal area for geography as a whole.

So, even more specialisation? An even stronger focus on a small subfield? Today, when the aim is not to take a specialist view but to take an overall view? This is precisely what Quaternary research is striving for, as we tried to explain above: an overall view of all questions related to the Quaternary period, an overall view that naturally cannot be limited to Germany but must include the entire world in its scope. But already today, this almost exceeds the working capacity of one individual. All over the world, research into the Quaternary as the geological formation of the present day has taken on an enormous scale. The pursuit of this research alone takes the full working capacity of a scientist.

Finally, there is one more thing to mention: the practical importance of Quaternary research. The fact that the Ice Age sands and gravels are the most important aquifers of the North German Plain and other glacial areas is well known. The Quaternary geologist must investigate the laws upon which the water-bearing strata occur. Only then is he in a position to advise the drilling contractor, the water expert etc. correctly. Water is today one of the most valuable natural resources. Its importance is increasing from day to day. The development and proper management of water resources is one of the most important tasks, especially in the densely populated cultural countries.

The situation is similar for the other natural resources found in the Quaternary formation, might these be peat bogs, marl deposits, diatomite deposits, sands, gravels, brick clays, etc. They all need to be studied in detail by the Quaternary researcher in terms of their distribution and occurrence. Only accurate scientific research of all these deposits provides the right conditions for their practical exploitation, and only this can protect the practice from failure, wrong investments and the like.

The fact that Quaternary research exists today as a science in its own right is also evidenced by the fact that not only individual researchers but entire research associations have been founded in this field all over the world, and that specialised journals for this science or subject sub-areas have been established ("Die Quartärperiode" [in Russian], "Die Eiszeit", "Quartär", "Zeitschrift f. Gletscherkunde", "Zeitschrift f. Geschiebeforschung" etc.). Before the last war researchers had joined forces in the "International Quaternary Association" founded in Copenhagen in 1928, which held further conferences in Leningrad (1932) and Vienna (1936).

The special importance of at least parts of Quaternary research has been recognised in other countries for some time, leading to the foundation of special research institutes. In France, for example, there is the large "Institut de Paleontologie humaine" for decades, which mainly works in the field of prehistory, which is particularly important in France. In Sweden, there is not only the "Geochronological Institute" in Stockholm, which is particularly concerned with the determination of time in the Quaternary period - partly also in older formations - but there and in Finland, for example, Quaternary research is a very important part of the university research and teaching (Post, Sauramo, etc.). In Russia, the Academy of Sciences has set up a special Quaternary department, which is only active in the field of Quaternary research works.

There is nothing similar in Germany so far. However, Germany is in a central position for Quaternary research, not only because it has a share in the two largest glaciation areas in Europe, the Northern European and the Alpine regions, but also because the important intermediate area between the two glaciations is located in Germany. In this intermediate area significant migrations and changes took place not only of mankind, but also of the flora and fauna. Due to its location, Germany has a very special obligation to conduct Quaternary research in the broadest sense. For this reason, there has long been a larger group of researchers in Germany who are particularly interested in the Quaternary period, but this group has so far lacked a narrower focus.

A portion of researchers interested in Northern Germany, and in particular those interested in its glacial erratics, joined together in the "Gesellschaft für Geschiebeforschung". This society publishes the "Zeitschrift für Geschiebeforschung" as a special institution. 17 volumes of this journal have so far been published. The "Zeitschrift für Gletscherkunde", which is available in 28 volumes, was mainly concerned with glaciological research, but also included Quaternary research. Unfortunately, the expensive price of the journal allowed only a few individuals to keep it. Shortly before the last war the journal "Quartär" was founded, of which 4 volumes have been published so far. It was intended to be a "Yearbook of Research on the Ice Age and its Cultures". Here too, further distribution failed due to the high price of the volumes. It would undoubtedly be desirable if, instead of the three journals, some of which had slightly different objectives but all of which were essentially devoted to Quaternary research, we had a single journal which could serve the entire Quaternary community and which could be priced in such a way that it would really benefit a wider audience.

After the war had cut the links with foreign researchers, various parties interested in the Quaternary period, especially from southern Germany, suggested closer coopera- 
tion among German researchers. In March 1948, the German Quaternary Association was founded in Hanover. The first major conference took place there in October 1948, which is reported on in the appendix to this yearbook.

The aim of the German Quaternary Association is to bring together researchers from the various sciences involved in the Quaternary period, geologists, geographers, botanists, zoologists, anthropologists, prehistorians, etc., in order to bring the manifold problems of the Quaternary period closer to a solution and thus, to contribute to understanding the present and our place in it. We hope that the time is not far off when the German Quaternary Association can become a member and part of a large International Quaternary Association. The worldwide dissemination of Quaternary phenomena, especially glaciations with all their effects, requires a global association of researchers, just as it was before the last war had begun to form. Only through the cooperation of researchers around the world will it be possible to bring the great problem of the Ice Age closer to a solution.

Review statement. This paper was edited by Frank Preusser. 